\title{
iPad with iPad-based Apps: An Optimal Communications Tool in the Intensive Care Unit?
}

\author{
Gautham M Raju(1)
}

Keywords: Augmentative and alternative communication, Communication tools, Critically ill, Intensive care unit, ipad, ipad apps. Indian Journal of Critical Care Medicine (2021): 10.5005/jp-journals-10071-24034

Computers and the use of related technology have been around in the intensive care unit (ICU) since the last few decades and have been steadily evolving in the range of their applications especially in assisting with patient communication. However, such technology has been largely used in monitoring of the patient rather than assisting proactive patient participation in their care, whether in terms of treatment or expression of specific aspects of distress faced especially in patients who are unable to communicate due to intubation/presence of artificial airway. Current literature suggests that in critically ill patients, apart from the physical disability, there is also an enormous negative psychological impact on the patients while undergoing treatment in ICU, extending well into the recovery period, with over $20 \%$ of survivors suffering from post-traumatic stress disorders (PTSD) and significant mental and physical health problems. ${ }^{1,2}$ This was magnified due to impairment in communication, especially during the COVID-19 pandemic due to use of PPE which acted as barrier and hampered visual, vocal, and auditory exchange between the patient and the caregiver. A study by Happ et al. ${ }^{3}$ conducted in six ICUs in the USA showed that about $50 \%$ of ICU patients retain the ability to communicate and have the potential to meaningfully interact with caregivers with the help of assistive communication techniques also known "augmentative and alternative communication" (AAC), but their usage has been limited in ICU patients. "Augmentative communication" is defined as being supplemental to speech, such as the use of gestures and facial expressions, whereas alternative communication refers to a complete reliance on other systems and techniques for communication purposes, such as speechgenerating devices." ${ }^{\prime 4}$ They can be no-tech, low-tech, or high-tech modes to aid communication. "No-tech" mode relies on facial expressions and voluntary movements (sign language); low-tech mode relies in paper, books, communication display boards containing images, words, commonly used phrases, or combination of all; or high-tech mode relies on electronic devices which can range from smart mobile devices to dedicated AAC technology integrating hardware and software. ${ }^{5}$ AAC can also be classified as aided or unaided depending on the use of tools or relying on human interaction alone, respectively. Associated devices can be fixed or mobile devices like iPad or any form of customized tablet. Studies are ongoing to enable the utilization of technology to enable nonverbal communication with critically ill patients and ease distress considerably.

In this issue of IJCCM, Andrew Dind et al. presented a "preclinical bench study" to assess the feasibility of the use of ipad as a high-tech, aided AAC tool with application of different ipad apps to assist communication. Different ipad apps, both paid and free,
Department of Critical Care, St John's Medical College and Hospital, Bengaluru, Karnataka, India

Corresponding Author: Gautham M Raju, Department of Critical Care, St John's Medical College and Hospital, Bengaluru, Karnataka, India, Phone: +91 9793004589, e-mail: drgauraju@gmail.com

How to cite this article: Raju GM. iPad with iPad-based Apps: An Optimal Communications Tool in the Intensive Care Unit? Indian J Crit Care Med 2021;25(11):1217-1218.

Source of support: Nil

Conflict of interest: None

from Apple app store were evaluated based on different features including suitability to ICU settings, ease of interaction in terms of readability and writability, language and phrase presets, textto-speech and speech-to-text assistance along with few others. Different apps have been compared against each other with respect to the aforementioned features to find the most suitable for application in ICU. It was observed that apps that have multiple sensory inputs and tools like "text to speech" have been particularly useful. Since it is a preclinical bench study, it was not possible to make specific ICU app recommendation, as features, tools, availability, and costs varied. However, the study may help provide insight into both the type of app as well as the additional tools within the app that may be necessary for productive communication between critically ill patients and their caregivers.

While the study lays emphasis on the need for effective AAC, limitations may arise. Possibility or constraints to uniform application in patients with different severity of illness, measured in terms of ICU severity scores like acute physiology and chronic health evaluation II score (APACHE II) that may hamper or influence useful communication needs attention. In ICU, patients frequently suffer from impaired ability to communicate due to reduced sensory acuity (visual, auditory, speech, or touch), reduced attention span, sedation, or presence of delirium, limiting the use of iPad and iPad apps. While the use of advanced technology is economically feasible and appreciable in developed nations, it may preclude the use of expensive gadgets or technology in resource-limited ICU settings. Another issue that may arise could be of training the caregiver who may not be familiar or comfortable enough to make effective use of the technology. Infection control can also be a major challenge with respect to the usage of "touch-based devices" in ICU. Perhaps it can be argued that things may improve with time and training; however, the overall compliance and final outcome will be known at the end of the study.

(c) The Author(s). 2021 Open Access This article is distributed under the terms of the Creative Commons Attribution 4.0 International License (https://creativecommons. org/licenses/by-nc/4.0/), which permits unrestricted use, distribution, and non-commercial reproduction in any medium, provided you give appropriate credit to the original author(s) and the source, provide a link to the Creative Commons license, and indicate if changes were made. The Creative Commons Public Domain Dedication waiver (http://creativecommons.org/publicdomain/zero/1.0/) applies to the data made available in this article, unless otherwise stated. 
The study while focusing on various features within the apps and ease of use in terms of interface and usability, it is important to acknowledge the dynamic nature of patients' condition and their ability to learn and adapt to new technology. AAC has been used in physically and mentally challenged patients in both subacute and chronic settings. Such patients and their caregivers have generous amount of time to work with and understand the different aspects of the technology like ipad or similar devices. ${ }^{6}$ However, in the ICU, caregivers may frequently find themselves in stark contrast to the aforementioned situation. Fluctuating cognitive status in critically ill patients who are in different stages of illness or recovery process can be challenging in achieving uniformity in successful ipad app usage. Any difficulty faced in understanding or interacting with the ipad may quickly lead to frustration in an already distressed patient and may lead to loss of motivation in both the patient and the caregiver, to persist in usage. Even if initially successful, consistency in subsequent use remains to be studied. The easy availability and the versatility of devices like ipad can mitigate the problems to a great extent.

The ipad has been in existence for about two decades now. Advances in technology and software have enabled their use in the medical field and its evolution. ipad and the apps have been initially used in postoperative patients. A feasibility study done in a postoperative care unit in Northeast US in a Cancer center over 6 months found more than $80 \%$ of patients were satisfied with communication by the use of aAC tool in the form of a customized tablet like ipad. ${ }^{7}$ But currently randomized control trials to suggest the use or efficacy regarding the same are limited; ${ }^{8}$ studies on large-scale application and active research into ipad apps or similar tools are necessary which can give necessary insights into evolving AAC tools further.

Every human being has an innate need to "understand and be understood." Its implications are heavier in ICU where patients suffer impairments in different sensory organs. Several researchers have offered solutions to make the best use of a critically ill patients ability by integrating hardware and software, "signal sensing and acquisition methods utilized in conjunction with the existing high-tech AAC platforms for individuals with a speech disability, including imaging methods, touch-enabled systems, mechanical and electromechanical access, breath-activated methods, and brain-computer interfaces $(\mathrm{BCl})$ " to help translate nonverbal communication effectively. ${ }^{9}$ ipad or similar tablet devices can provide simple interface and the apps can be designed with multiple built in questionnaires with multi-language support, specifically keeping critically ill patients in mind. Hardware and software advances in the ipad like "artificial intelligence" and "machine learning" can be leveraged to make "bench to bedside" evolution and adoption of assistive communication tools plausible sooner than later.

\section{The Bottom Line}

Effective communication by critically ill is a long-standing problem and a constant challenge with a significant impact on clinical outcomes. While AAC has been assisting communication, there cannot be a "one size fits all" approach to critically ill patients. AAC application may be "low-tech and/or high-tech," "aided/unaided" or a combination depending on the human activity assistive technology (HAAT) model which recommends integration of all factors like the human (patient and/or caregiver), activity, context and severity of illness, and type of assistive technology that is being applied..$^{10}$ Efficiency can be improved by the process of selecting an assistive technology solution, by the caregiver carrying out an activity in an appropriate context. Different methods can be combined in the form of a standardized framework or algorithm to approach the selection of communication tools. ${ }^{11}$

The importance of AAC in patients both acutely and chronically ill is acknowledged by the International Society of Augmented and Alternative Communication (ISAAC), by consensus, in observing October every year as "AAC awareness month." The ISAAC theme for 2021 "Get out, speak up, and breakthrough the screen in a recovering world"12 is very apt with regard to breaking new ground in AAC research and application at the bedside, particularly in critically ill patients. Customized solutions with integrated multi-modal assistive technology will be the way forward. ${ }^{13}$

\section{ORCID}

Gautham M Raju (1) https://orcid.org/0000-0002-4747-3564

\section{References}

1. Khalaila R, Zbidat W, Anwar K, Bayya A, Linton DM, Sviri S. Communication difficulties and psychoemotional distress in patients receiving mechanical ventilation. Am J Crit Care 2011;20(6):470-479. DOI: 10.4037/ajcc2011989.

2. Baumgarten M, Poulsen I. Patients' experiences of being mechanically ventilated in an ICU: a qualitative metasynthesis. Scand J Caring Sci 2015;29(2):205-214. DOI: 10.1111/scs.12177.

3. Happ MB, Seaman JB, Nilsen ML, Sciulli A, Tate JA, Saul M, et al. The number of mechanically ventilated ICU patients meeting communication criteria. Heart Lung 2015;44(1):45-49. DOI: 10.1016/ j.hrtlng.2014.08.010.

4. Beukelman DR, Fager S, Ball L, Dietz A. AAC for adults with acquired neruological conditions: a review. Augment Altern Commun 2007;23(3):230-242. DOI: 10.1080/07434610701553668.

5. Cook AM, Polgar JM. Assistive technologies principles and practices, 4th ed. New York, NY, USA: Elsevier; 2015.

6. Skär L, Söderberg S. The use of information and communication technology to meet chronically ill patients' needs when living at home. Open Nurs J 2011;5:74-78. DOI: 10.2174/18744346011 05010074.

7. Brunner TH, DiFortuna K, LeTang M, Murphy J, Stemplewicz K, Kovacs $M$, et al. Feasibility of an ipad to facilitate communication in postoperative patients with head and neck cancer. J Perianesth Nurs 2018;33(4):399-406. DOI: 10.1016/j.jopan.2016.10.008.

8. Mobasheri MH, King D, Judge S, Arshad F, Larsen M, Safarfashandi Z, et al. Communication aid requirements of intensive care unit patients with transient speech loss. Augment Altern Commun 2016;32(4): 261-271. DOI:10.1080/07434618.2016.1235610.

9. Elsahar Y, Hu S, Bouazza-Marouf K, Kerr D, Mansor A. Augmentative and alternative communication (AAC) advances: a review of configurations for individuals with a speech disability. Sensors (Basel) 2019;19(8):1911. DOI: 10.3390/s19081911.

10. Giesbrecht E. Application of the human activity assistive technology model for occupational therapy research. Aust Occup Ther J 2013;60(4):230-240. DOI: 10.1111/1440-1630.12054.

11. Ten Hoorn S, Elbers PW, Girbes AR, Tuinman PR. Communicating with conscious and mechanically ventilated critically ill patients: a systematic review. Crit Care 2016;20(1):333. DOI: 10.1186/s13054016-1483-2.

12. Available from: https://isaac-online.org.

13. Dind AJ, Starr JS, Arora S. ipad-based Apps to Facilitate Communication in Critically III Patients with Impaired Ability to Communicate: A Preclinical Analysis. Indian J Crit Care Med 2021;25(11):1232-1240. 